\title{
Novel Prototype of Mining Helmet to Facilitate Cooling
}

\author{
Hanumesha Pujar, Syed Suhel, Naveen Dinakar, Chetan Baseganni", Mayur Gohil, Rahul Kulkarni \\ Department of Mechanical Engineering, K.L.E.I.T. - Hubballi, Karnataka, India
}

\author{
doi: https://doi.org/10.21467/ajgr.3.1.3-8 \\ *Corresponding Author email: \\ chetancb07@gmail.com \\ Article Histary \\ Received: 02 August 2017 \\ Revised: 05 August 2017 \\ Accepted: 14 August 2017 \\ Published: 14 August 2017

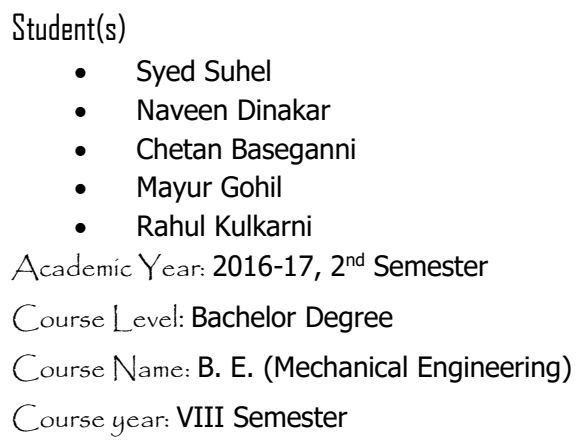

- $\quad$ Syed Suhel

- Naveen Dinakar

- Chetan Baseganni

- Mayur Gohil

- Rahul Kulkarni

Academic Year: 2016-17, $2^{\text {nd }}$ Semester

Course Level: Bachelor Degree

Course Name: B. E. (Mechanical Engineering)

Course year: VIII Semester

Mentor(s)

- Hanumesha Pujar

\begin{abstract}
The thermal comfort of mining helmet during mining process is important as it can affect the physiological and psychological condition of the worker. Project deals with the development of cooling system for mining helmet using powerful fan technology. The system consists of mainly two fans and batteries. Electrical power is used to run the fan, which creates a temperature difference inside the helmet and facilitates cooling. Fans are used to suck the air from the surrounding and air is circulated inside the helmet and provides a soothing cool breeze inside the helmet. The numerical and experimental results indicate that the temperature inside the helmet can be reduced by $4-5{ }^{\circ} \mathrm{C}$ in approximately $3-4$ minutes in the mining helmet.
\end{abstract}

Keywords: Thermal cooling, Electrical power, Temperature difference.

\section{Introduction}

A helmet is a sort of protecting gear worn to protect head from injuries. Helmets are used for recreational activities and sports (e.g. jockeys in horse racing, football, ice hockey, cricket, baseball, hurling and rock climbing) dangerous work activities (e.g. construction, mining, riot police) and transportation (e.g. bike helmets and bicycle helmets). Until 1990s, most helmets are made of resin or plastic, which may be reinforced with fibers. Need for ventilation in helmet has been the need of the hour for various fields. Study has been performed on the ventilation of bicycle helmets. We have that intuitively important factors such as vent cross-section or exposed scalp surface are often limited in their impact by other parameters. This and wide variability in helmet performance indicate that suboptimal combinations of relevant factors reduce the ventilation of most helmets under the conditions studied [1]. Development of motor cyclist helmet cooling using thermoelectric module was carried out by M. Hrairi [2]. Safety and cooling are the major aspects while design and development of mining helmet. Development of mining helmet is limited only to safety; these developments are highly focused to make helmet smarter. Smart Helmet Using RF and WSN Technology for Underground Mines Safety is focused to make miner's helmet smarter by 
incorporating RF and WSN technology so as to make enhance better communication and warning systems [3]. Helmets now for cooling purpose in sports field use thermoelectric material and also a cushion lining for insulation, heat from the liquid cushion is removed by using a 12 volt thermoelectric module [4]: According to research carried by Rasch W, here he uses four male subjects and carrier out his experiment during the idle condition and during increment exercise at 515 and 25 degree C. In his results, he showed that the heat loss from head skin and expired air decreased with increasing temperature, and heat loss from the head was larger than the heat brought to the brain by the arterial blood during hyperthermia [5]. Helmet cooling system consists of a receptacle containing coolant through which air is passed which is transmitted to helmet via flexible hose [6]. To control the thermal comfort of helmet users Saud Ghani analyzed the utilization of forced convection and Phase Changing Material (PCM). An experimentally validated threedimensional Computational Fluid Dynamics (CFD) model of an industrial helmet and a human head was utilized to assess the helmet thermal performance under different harsh working environments [7].

Nevertheless, given the large variation in designs in market, there is no widely adopted systematic approach to designing miner's helmets for optimal ventilation. This paper deals to address each of the above issues in the attempt to design and build a thermoelectrically cooled mining helmet. The primary goal of this work is to design and develop an air-conditioned mining helmet using a thermoelectric module capable of cooling the internal temperature of the helmet by reducing the internal temperature by 4-5 degree Celsius. This goal was attempted using a number of mechanical and electrical systems.

\subsection{Design aspects}

The first stage of the conceptual process was to determine which aspects of the helmet design would be considered. The design and build process revolved mainly around the cooling system and process control with almost all resources devoted to these aspects. It was necessary to consider structural integrity and safety of the miner.

\subsection{Fan selection criteria}

$>$ Size. It was required that fans to be compact enough to fit in desired locations without compromising stability, aesthetics or functionality of the helmet.

Dlow rate. The volumetric flow rate of selected fans matched that used in design Calculations, at the static pressure loss. It was required that the fans maintain a total volumetric flow rate of $0.01 \mathrm{~m}^{3} / \mathrm{s}$.

$>$ Power Consumption. It was ideal that fans had minimal power usage to allow a Reasonable battery operation life.

$>$ Noise level. Excessive noise inside the helmet was deemed to be unacceptable. The Most suitable fans from several of the major suppliers were directly compared. Specifications of the selected fan is given in Table 1.

Table 1: Specifications of the fan

\begin{tabular}{|c|c|}
\hline Operating voltage & $12 \mathrm{~V} \mathrm{DC}(8 \mathrm{~V}-13.8 \mathrm{~V})$ \\
\hline Power consumption & $0.05 \mathrm{~A} / 0.6 \mathrm{~W}$ \\
\hline Temperature range & $-20 \mathrm{deg} \mathrm{C}$ up to $+70 \mathrm{deg} \mathrm{C}$ \\
\hline Speed & $1000 \mathrm{RPM}$ \\
\hline Air flow & $28 \mathrm{cbm} / \mathrm{h}$ \\
\hline Sound pressure level & $25 \mathrm{~dB}$ \\
\hline Weight & $430 \mathrm{~g}$ \\
\hline
\end{tabular}

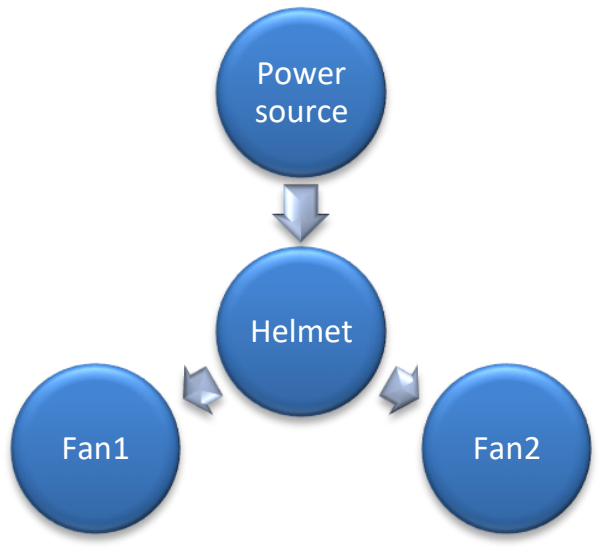

Figure 1: Block diagram of helmet cooling 


\subsection{Construction of Temperature Control Helmet}

The construction of the test assembly was a time-consuming operation. With the basic shell shape formed from a mould, many alterations were performed to accommodate the installation of the electrical components. Block diagram of helmet cooling system is given in Figure 1. The processes involved in constructing the test helmet and gives an insight into the problems that were encountered along the way and their respective solutions was considered carefully.

\subsubsection{The Cooling Chamber}

The cooling chamber is the conventional helmet, in which slots are made exactly to the size of the fan diameter to accommodate them. The helmet is made of mould injected plastic. Two through slots are made at the top of the helmet with sufficient spacing between them. Each slot accommodating a Fan model EMB-Papst 712F which blows cool air from the outside into the chamber. Since, focus was only achieving cooling effect inside the cooling chamber the integrity and strength of the helmet shell was no taken much into consideration. But, if a helmet is moulded according to our design requirements then the integrity and strength of the helmet shell will be maintained. And also, the miner's safety will be maintained.

\subsubsection{Positioning of the Power Supply}

We tried different methods of placing the power supply for the fan to work effectively and came up to numerous conclusion for it, but ultimately, we decided to create a rectangular shape cavity in the helmet at the back side so as to place the battery in it. A switch was also added.

\section{Experimental Setup}

The experimental setup of cooling chamber is shown in the Figure 2. The setup consists of two Fan model EMB-Papst 712F \& two 9v battery source. Fans are fixed inside the helmet by screws, wires are attached to them and are extended to the cavity where the battery is to be placed. The wires are attached to a switch to operate both fans, respective connections are made when switches are turned on and the fans operate. A temperature sensor unit is inserted inside the helmet to check the temperature change inside the helmet and the readings are noted down in the tabular column.

\subsection{Formulae [8] Used for Calculation}

\section{Heat dissipated $Q=h A \Delta T$}

where h- Heat transfer coefficient $\left[\mathrm{W} / \mathrm{m}^{2}{ }^{\circ} \mathrm{C}\right]$

A- Surface area of helmet $\left[\mathrm{m}^{2}\right]$

$\Delta \mathrm{T}$ - Temperature gradient $\left[{ }^{0} \mathrm{C}\right]$

2. Heat transfer coefficient $h=[\mathrm{NuK}] / \mathrm{d}$

where $\mathrm{N}_{\mathrm{u}}$ - Nusselt number

$\mathrm{K}$ - Thermal conductivity $\left[\mathrm{W} / \mathrm{m}^{0} \mathrm{C}\right]$

$d$ - Diameter of helmet [m]

3. Nusselt number $N_{u}=0.625\left[\operatorname{Re}_{D} P_{r}\right]^{0.4}$

where $\operatorname{Re}_{D}$ - Reynolds number

$\mathrm{P}_{\mathrm{r}}$ - Prandtl number

\section{Reynolds number $\operatorname{Re}_{D}=[\rho V d] / \mu$}

where $\rho$ - Density of air $\left[\mathrm{Kg} / \mathrm{m}^{3}\right]$

$\mathrm{V}$ - Velocity of air $[\mathrm{m} / \mathrm{sec}]$

$\mu$ - Absolute Viscosity [Ns/ $\left.\mathrm{m}^{2}\right]$

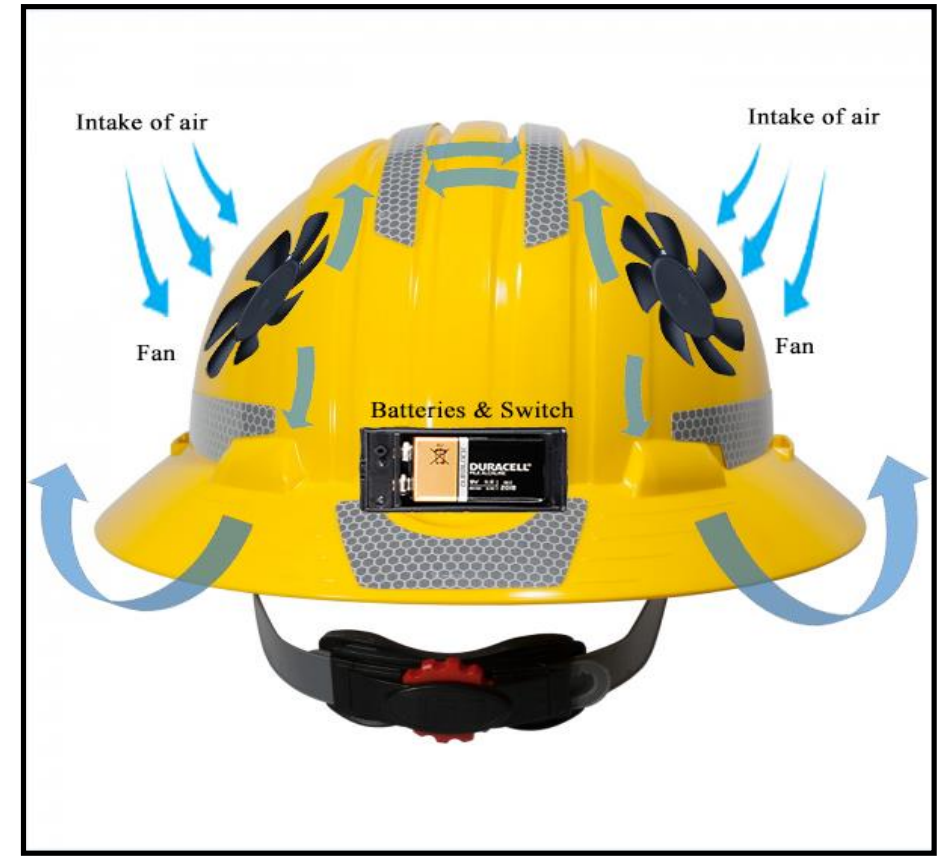

Figure 2: Experimental model 
Table 2: Experimental results

\begin{tabular}{|c|c|c|c|c|}
\hline Sl.No & Time in sec & $\begin{array}{c}\text { Surrounding } \\
\text { temperature in } \\
\text { Celsius }\end{array}$ & $\begin{array}{c}\text { Heat transfer } \\
\text { coefficient in } \\
\mathbf{W} / \mathbf{m}^{\mathbf{2}} \mathbf{C}\end{array}$ & $\begin{array}{c}\text { Heat dissipated in } \\
\text { Joules/sec }\end{array}$ \\
\hline 1 & 0 & 48 & 26.93 & 18.06 \\
\hline 2 & 10 & 48 & 26.93 & 18.06 \\
\hline 3 & 20 & 48 & 26.93 & 18.06 \\
\hline 4 & 30 & 48 & 26.93 & 18.06 \\
\hline 5 & 40 & 48 & 26.93 & 18.06 \\
\hline 6 & 50 & 48 & 26.93 & 18.06 \\
\hline 7 & 60 & 48 & 26.93 & 18.06 \\
\hline 8 & 70 & 48 & 26.93 & 18.06 \\
\hline 9 & 80 & 48 & 26.93 & 18.06 \\
\hline 10 & 90 & 48 & 26.93 & 18.06 \\
\hline 11 & 100 & 48 & 26.93 & 18.06 \\
\hline 12 & 110 & 49 & 26.85 & 19.396 \\
\hline 13 & 120 & 49 & 26.85 & 19.396 \\
\hline 14 & 130 & 49 & 26.85 & 19.396 \\
\hline 15 & 140 & 49 & 26.85 & 19.396 \\
\hline 16 & 150 & 50 & 26.80 & 20.74 \\
\hline 17 & 160 & 50 & 26.80 & 20.74 \\
\hline 18 & 170 & 50 & 26.80 & 20.74 \\
\hline 19 & 180 & 50 & 26.80 & 20.74 \\
\hline
\end{tabular}

\section{Results and Discussion}

The temperature rise in the surrounding is observed and noted down as shown in the Table 2. The temperature rise is observed for 180 seconds. The temperature increases from $48{ }^{\circ} \mathrm{C}$ to $50{ }^{\circ} \mathrm{C}$ in 180 seconds. The rise in the temperature is not constant. It varies from one position to other depending upon the geological conditions of the site. The rate of temperature rise increases after 110 and 150 seconds of operation.

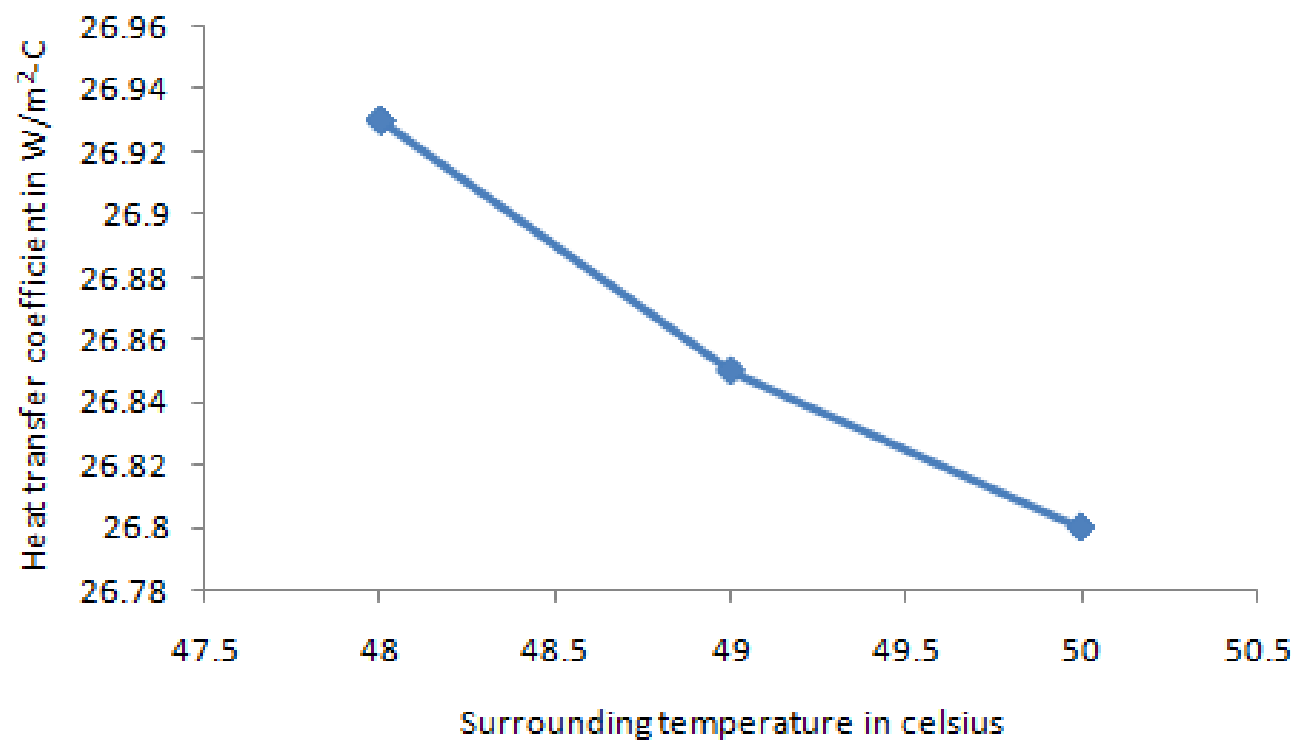

Figure 3: Temperature $v / s$ Heat transfer coefficient 
Pujar et al., Adv. J. Grad. Res.; Vol. 3 Issue 1, pp: 3-8, January 2018

Variation of heat transfer co-efficient with respect to surrounding temperature change is as shown in the Figure 3. Heat transfer co-efficient decreases with increase in surrounding temperature from $26.93 \mathrm{~W} / \mathrm{m}^{2}$ ${ }^{\circ} \mathrm{C}$ at 10 seconds to $26.86 \mathrm{~W} / \mathrm{m}^{2}{ }^{\circ} \mathrm{C}$ at 180 seconds. As the heat transfer coefficient is inversely proportional to change in temperature we observe decrease it heat transfer coefficient.

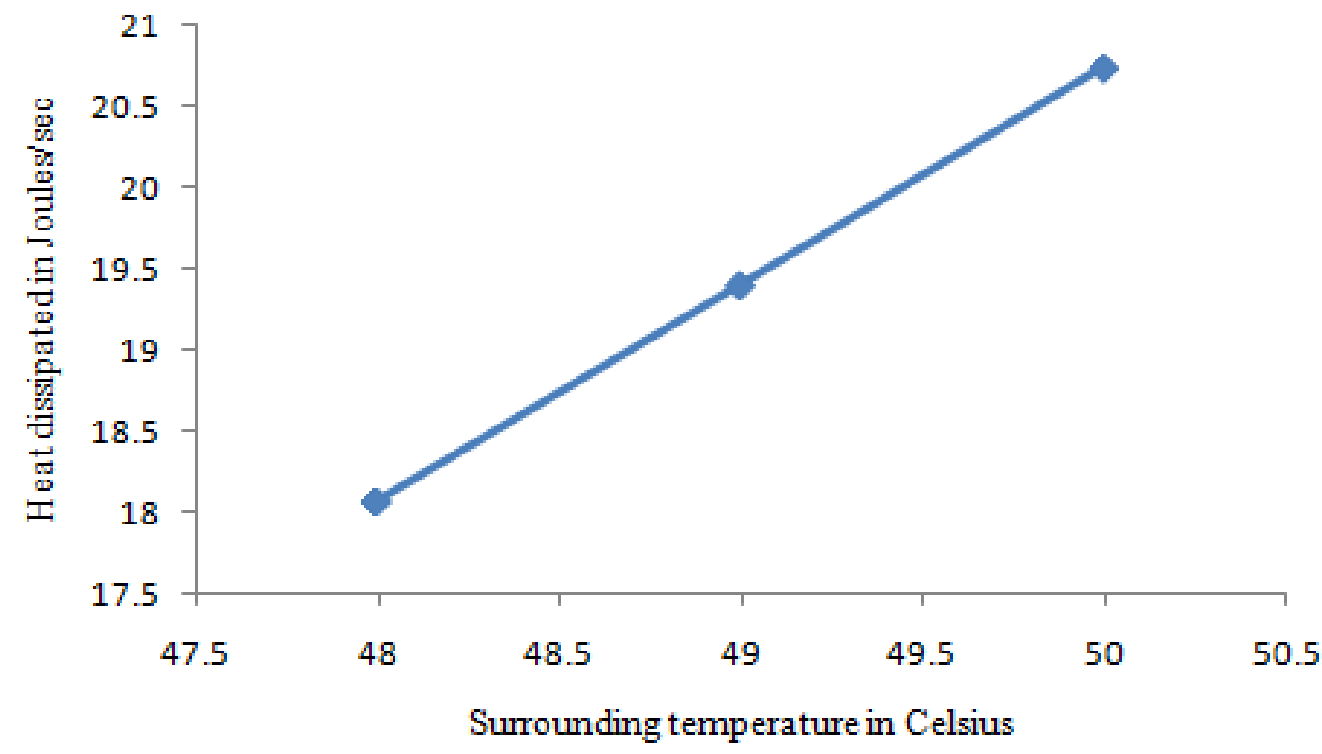

Figure 4: Temperature $v / s$ Heat dissipated

Variation of heat dissipated with respect to surrounding temperature change as shown in the Figure 4. Heat dissipated increases with increase in temperature from $18.06 \mathrm{~J} / \mathrm{s}$ at 0 seconds to $20.74 \mathrm{~J} / \mathrm{s}$ at 180 seconds. As temperature increases in the surrounding the temperature difference also increases leading to greater heat dissipation from lower to higher temperature region.

\section{Conclusions}

A physical prototype Model of mining helmet was developed to facilitate cooling. This paper deals with development of cooling system for mining helmet using powerful fan technology. The temperature is reduced by $3-4^{\circ} \mathrm{C}$ in 3 minutes. The results are validated as temperature, increases correspondingly heat transfer coefficient decreases. As the temperature increases the heat dissipation to the surrounding also increases correspondingly.

\section{Acknowledgement}

We are thankful to Dr. S. N. Mathad, Head \& Prof. Department of Physics, KLEIT Hubballi. For his encouragement, effective guidance and valuable suggestions right from the beginning of the project, without which this project work would not have been accomplished. We are greatly indebted to him. We would like to express our heart full thanks to all the lecturers and staff members of the department of mechanical engineering for constructive suggestion and constant encouragement. We also thank to our parents and all our friends wholeheartedly who have rendered their help, motivation and support to accomplish this project.

\section{How to cite this article:}

Pujar, H., Suhel, S., Dinakar, N., Baseganni, C., Gohil, M., \& Kulkarni, R. (2017). Novel Prototype of Mining Helmet to Facilitate Cooling. Advanced Journal Of Graduate Research, 3(1), 3-8. doi: https://doi.org/10.21467/ajgr.3.1.3-8 


\section{References}

[1] Hem Chandra Joshi and Satyajit Das, "Design and Simulation of Smart Helmet for Coal Miners using Zigbee Technology," International Journal on Emerging Technologies, vol.8, no.1, pp.196-200, 2017.

[2] M. Hrairi, A.F. Abdullah and M.I. Ahmed, "Cooling of Motorcyclist Helmet with Thermoelectric Module," Middle-East Journal of Scientific Research, vol.13, pp. 103-108, 2013.

[3] Shabina.S, "Smart Helmet Using RF and WSN Technology for Underground Mines Safety," 2014 International Conference on Intelligent Computing Applications, pp.305-309,2014.

[4] David Dearing, 4945 Dana Dr., Kennesaw' Ga- 30144 "United States Patent" Patent Number: 5,146,757.

[5] Rasch W et al."Heat Loss from the Human Head During Exercise," Journal of Applied Physiology, vol. 71, no 2, pp.590-595, Aug 1991.

[6] Deb, A. and Biswas, U et al. "Evaluation of safety of helmets using a featureless Hybrid III head form," Int. J. Vehicle Safety, vol.1, no. 4, 2006 .

[7] Saud Ghani et al. "The effect of forced convection and PCM on helmets' thermal performance in hot and arid environments, " Applied Thermal Engineering, vol. 111, no 25, pp. 624-637, 2017.

[8] C.P. Kothandaraman, S. Subramayan, "Heat and Mass Transfer DATA Book" New Age International Publication $6^{\text {th }}$ Edition.

\section{Publish your research article in AIJR journals-}

$\checkmark$ Online Submission and Tracking

$\checkmark$ Peer Reviewed

$\checkmark$ Rapid decision

$\checkmark$ Immediate Publication after acceptance

$\checkmark$ Open Access (Articles freely available online)

$\checkmark$ Retain full copyright of your article.

Submit your article at journals.aijr.in 